\title{
Assessment of the Hazelnuts Roasting Process by Pressure Differential Scanning Calorimetry and MID-FT-IR Spectroscopy
}

\author{
Hanna Ciemniewska-Żytkiewicz • Joanna Bryś • \\ Katarzyna Sujka • Piotr Koczoń
}

Received: 20 October 2014 / Accepted: 15 February 2015 / Published online: 6 March 2015

(C) The Author(s) 2015. This article is published with open access at Springerlink.com

\begin{abstract}
The effect of the roasting process on the quality of hazelnuts (Corylus avellana L.) lipidic fraction was investigated by pressure differential scanning calorimetry (PDSC) and middle Fourier transform infrared (MID-FT-IR) spectroscopy. The data obtained were referred to and related with fatty acid composition, free fatty acids content, peroxide value, anisidine value and tocopherols concentration measured by standard techniques. These methods were used to decipher between the roasted hazelnuts (shelled and in-shell) treated in different thermal conditions $\left(100{ }^{\circ} \mathrm{C}, 130^{\circ} \mathrm{C}\right.$ and $\left.160{ }^{\circ} \mathrm{C}\right)$ and time (10, 30 and $60 \mathrm{~min})$. The results of free fatty acids (FFA), peroxide value (PV) and anisidine value remained low for all roasting conditions applied and were within quality requirement ranges. The shell left on hazelnuts during the roasting process limited hazelnuts oxidative deterioration, hence it showed protective function. Minor changes occurred in the fatty acid and tocopherol contents and compositions. PDSC, as an appropriate unbiased method for assessing the oxidative stability, revealed a slight elevation of oxidative stability as the temperature and time of the roasting process increased $(p<0.05)$. Discriminant models constructed with the use of principal components (PC) procedure confirmed the ability of MID-FT-IR to monitor the roasting process within a certain range of temperature and time applied.
\end{abstract}

Keywords PDSC · Oxidation stability · MD-FT-IR · PV . AV · FAA · Tocopherols

H. Ciemniewska-Żytkiewicz $(\varangle) \cdot J$. Bryś $\cdot$ K. Sujka $\cdot$ P. Koczoń Department of Chemistry, Faculty of Food Sciences, Warsaw University of Life Sciences (SGGW), 166 Nowoursynowska Street, 02-787 Warsaw, Poland

e-mail: hanna_ciemniewska_zytkiewicz@sggw.pl

\section{Introduction}

Hazelnuts (Corylus avellana L.) which have a unique and unrivalled flavour are used as an additive in a variety of food products, such as, confectionary, chocolate, biscuits, both in a raw and roasted form (Donno et al. 2013; Demir and Cronin 2005). Due to the complete dehydration (CiemniewskaŻytkiewicz et al. 2014a; Perren and Escher 1997) which induces their specific organoleptic properties, such as, taste and crunchiness, hazelnuts are generally preferred roasted (Demir and Cronin 2005). The roasted hazelnuts might differ in both chemical and physical properties, as the roasting conditions commonly used by processors are widely ranged in both temperatures, $100-160{ }^{\circ} \mathrm{C}$ and times, $10-60 \mathrm{~min}$. Therefore, deciding upon a robust analytical system to allow for objective, control of roasted hazelnut quality is necessary. For the processing industry, it is crucial to predict the impact of roasting conditions, e.g. the time and temperature have a major impact on the hazelnut's quality attributes like moisture, colour and rancidity (Özdemir and Devres 2000). The oxidative stability determines the shelf life of roasted nuts as well as manufactured products containing roasted nuts (Perren and Escher 1997).

Nuts and oilseeds contain oil with a high amount of unsaturated fatty acids. Thus, the oil represents the most sensitive component in regard to oxidation, which in turn limits shelf life and sensory characteristics of the roasted products. The retention of the oxidative stability of roasted products, as a balance between the high unsaturated fatty acids content and changing antioxidant capacity, is an important issue in industrial nut manufacturing (Özdemir and Devres 1999; Perren and Escher 1997; Amaral et al. 2006).

Differential scanning calorimetry (DSC) measures the heat flow associated with transition of state of the sample (material) as a function of time and temperature. As a result, unique energy profile of sample is obtained (Tan et al. 2002). DSC 
technique coupled with a pressure cell (PDSC - pressure differential scanning calorimetry) have the potential to be used as an accelerated thermal method to determine oil quality. It has previously been successfully used for hazelnut oil quality assessment (Ciemniewska-Żytkiewicz et al. 2014b).

The major advantages of Fourier transform infrared (FTIR) spectroscopy over other techniques include fast and easy equipment operation along with the possibility to conduct non-destructive analyses on samples at any state (solid, liquid, paste, gas) with convenient and environmentally friendly sample preparation (Bevilacqua et al. 2013). Originally, FT-IR has been used for pure sample analysis exclusively; however, recently, it has been successfully used for mixture analysis as well. The FT-IR procedure includes both reference (Sherazi et al. 2009) and discriminant analysis (Yang et al. 2005). Once the statistical model for a given type of mixture is established, measuring the amount of a given substance or discriminating of samples requires registration of one spectrum only followed by entering spectral data into a dedicated software.

Few studies about the fatty acid composition and tocopherol level changes during the roasting process of hazelnuts have already been reported (Amaral et al. 2006; Alasalvar et al. 2010), however, the roasting of hazelnut varieties grown in Poland has not been studied at all, to our knowledge. The objectives of this study was to assess the oxidative stability of roasted hazelnuts using PDSC methodology combined with more common fatty acids and tocopherol determinations and middle FT-IR (MID-FT-IR) spectroscopy analysis referred to classic quality oil assessments.

\section{Material and Methods}

\section{Reagents and Standards}

All the solvents and reagents were purchased from P.O.Ch Co. (Gliwice, Poland); standard compounds were supplied by Sigma-Aldrich (Saint Louis, MO, USA). All solvents and reagents used in the analyses were of chromatographic or analytical grade.

\section{Samples}

The samples analysed were of the Kataloński hazelnut (Corylus avellana L.) variety, collected from the orchard located in the south of Poland (Jankowice, Pszczyna $50^{\circ} 0^{\prime} 5^{\prime \prime} \mathrm{N}$ $18^{\circ} 59^{\prime} 18^{\prime \prime} \mathrm{E}$ ) in 2012. Hazelnuts in shell, classified in "Extra" class according to Commission Regulation (EC) No $1284 / 2002$, with a diameter equal to or above $16 \mathrm{~mm}$, were exclusively included in this study. In-shell fruits were collected at technological maturity, sun-dried for 3 days $\left(20-25^{\circ} \mathrm{C}\right)$ and then stored in shell at $4{ }^{\circ} \mathrm{C}$ until they were analysed.
Hazelnuts Roasting

Hazelnuts were roasted (shelled and in-shell forms) at nine specific temperature/time conditions: $100{ }^{\circ} \mathrm{C} / 10 \mathrm{~min}$, $100{ }^{\circ} \mathrm{C} / 30 \mathrm{~min}, 100{ }^{\circ} \mathrm{C} / 60 \mathrm{~min}, 130{ }^{\circ} \mathrm{C} / 10 \mathrm{~min}, 130{ }^{\circ} \mathrm{C} /$ $30 \mathrm{~min}, 130{ }^{\circ} \mathrm{C} / 60 \mathrm{~min}, 160{ }^{\circ} \mathrm{C} / 10 \mathrm{~min}, 160{ }^{\circ} \mathrm{C} / 30 \mathrm{~min}$, $160{ }^{\circ} \mathrm{C} / 60 \mathrm{~min}$, at a constant air flow rate $\left(0.8-1.0 \mathrm{~m} \times \mathrm{s}^{-1}\right)$. These conditions were set according to the range commonly used in the hazelnut industry. The average air flow was determined using Kestrel 4000 (Nielsen-Kellerman) anemometer. Roasting was conducted in a laboratory convective dryer, Memmert UFP400. Every roasting process was duplicated. After roasting, nuts were cooled immediately and stored at $-18{ }^{\circ} \mathrm{C}$ until they were analysed.

\section{Oil Extraction}

Cold pressing was performed using an oil expeller (Piteba, Nederlands), and then the oil was centrifuged at $4000 \mathrm{rpm} /$ 20 min at $4{ }^{\circ} \mathrm{C}$. The obtained oils were stored in $-18{ }^{\circ} \mathrm{C}$ with no light access until they were analysed.

\section{Basic Quality Analyses of Hazelnut Oils}

Hazelnut oil samples were initially characterized by basic quality parameters according to the ISO standard methods. The peroxide value (PV) of oils were determined by iodometric technique, the free fatty acids (\%FFA) by titration with $0.1 \mathrm{M}$ ethanolic potassium hydroxide and the anisidine value (AV) spectrophometrically, in accordance with standards ISO 3960:2007, ISO 660:2009 and ISO 6885:2012, respectively.

\section{Fatty Acids Determination}

The fatty acid composition of hazelnut oil was determined as fatty acid methyl esters (FAMEs) by alkaline treatment and capillary gas chromatography analysis, as described by Christie (1982). The chromatographic conditions were the same as reported by Bryś et al. (2013). The results were expressed as relative percentages of each fatty acid, calculated by external normalization of the chromatographic peak area. Fatty acids were identified by comparing the relative retention times of FAME peaks with FAME chemical standard.

\section{PDSC Determination}

The oxidative stability of the tested oils were determined using differential scanning calorimeter (DSC Q20, TA Instruments) coupled with a high-pressure cell (Q20P) as reported previously by Ciemniewska-Żytkiewicz et al. (2014b). The isothermal temperature for each sample was programmed at temperature $140{ }^{\circ} \mathrm{C}$. 


\section{Tocopherols Determination}

Due to tocopherols determination, approximately $300 \mathrm{mg}$ of hazelnut oil was dissolved in $1 \mathrm{~mL}$ of $\mathrm{n}$-hexane, respectively, and then extracts were filtered through a $0.45-\mu \mathrm{m}$ nylon filter. The tocopherols were determined by HPLC (Agilent 1200 series, Palo Alto, CA, USA) equipped with a fluorimeter detector (Agilent, Palo Alto, CA, USA). The excitation wavelength was $290 \mathrm{~nm}$, and the emission one was $325 \mathrm{~nm}$. The column used was a Luna Hilic Phenomenex column (250× $4.6 \mathrm{~mm}$ i.d., $5 \mu \mathrm{m}$ particle size) in isocratic conditions as reported by Gómez-Caravaca et al. (2010). The calibration curve was constructed with $\alpha$-tocopherol standard solution, and it was used for quantification.

\section{MID-FT-IR Spectroscopy Analysis}

Infrared spectra were registered for every sample in the classic range of $4000-400 \mathrm{~cm}^{-1}$ with $1 \mathrm{~cm}^{-1}$ resolution, using System 2000 Perkin Elmer spectrophotometer. The Grams AI 8.0 and TQ Analyst 8 software were used for spectral data processing, statistical modelling and evaluation. Samples of hazelnut oils extracted from roasting samples were registered as a film between two KRS plates. Samples were placed on a plate as a single drop of volume $0.05 \mathrm{~mL}$. Registration of 10 spectra for each sample with 20 scans for every spectrum was followed by spectra averaging and processing of the averaged spectrum.

\section{Statistical Analysis}

Relative standard deviation was obtained, where appropriate, for all data collected. All chemical analyses were carried out in triplicate $(n=3)$ for each sample. In the case of oxidation stability determination, for each oil at each time and temperature conditions, three experiments were performed and the average $\tau_{\max }$ (PDSC maximum induction time) values were calculated. The data were statistically processed using the analysis of variance with use of Tukey's test, considering a level of significance of less than $5 \%(p<0.05)$ with the use of Statgraphics Plus for Windows software, version 4.1 (Statistical Graphics Corporation, Warrenton, VA, USA). Discriminant models were calculated based on principal components analysis (PCA) with the use of the mean centering technique. Eight to ten principal components representing at least $95 \%$ of total variability of the samples spectral data, both frequencies and intensities, were used to construct multi-linear models to allow distinguishing between samples of different chemical composition. Regions representing the highest variations were applied instead of whole spectral region. Mahalanobis distances were used to evaluate membership of a sample to a given group. Performance index (PI) was calculated to every trial with focus on finding the highest value.

\section{Results and Discussion}

\section{Oxidative Stability of Roasted Hazelnuts}

Hazelnuts roasting leads to a number of flavour, sensory and physical alternations, oxidation metabolites formation, as well as, biochemical changes, such as lipid structure modifications (Amaral et al. 2006). The free fatty acid concentration (\%FFA), peroxide value (PV), anisidine value (AV) and calculated total oxidation value (TOTOX) of the oils extracted from roasted hazelnuts are gathered in Table 1.

The amount of FFA is a widely accepted indicator of oils and fats quality and represents progress of triglycerides hydrolysis. Accordingly to preliminary considerations, the highest level of \%FFA were observed for oils extracted from hazelnuts in $160{ }^{\circ} \mathrm{C}$ for $60 \min (p<0.05)$; however, the \%FFA occurred to be very low for all oils tested. Hence, the \%FFA levels in oils extracted from roasted hazelnuts are only slightly affected by the high-temperature treatment. PV is the well recognised indicator for primary oxidation (Gharby et al. 2011) which shows the amount of hydroperoxides present. The PV values for cold-pressed oils, including hazelnut oils, should not exceed $15 \mathrm{meqO}_{2} / \mathrm{kg}$ of oil (Codex Alimentarius 2013). The results of PV obtained, herein, remained low $(<2.5$ $\mathrm{meqO}_{2} / \mathrm{kg}$ of oil) for all roasting conditions applied, which is within quality requirements range. Under the influence of unfavourable conditions, such as long-term heating, applying a too high temperature or extreme exposure to light, the hydroperoxides break down to carbonyl compounds (alpha-beta unsaturated aldehydes) of low molecular mass. The content of these secondary oxidation products can be measured using the anisidine value. The significant increase in $\mathrm{AV}$ values with an increase in roasting time was observed for 130 and $160^{\circ} \mathrm{C}$, for both shelled and in-shell hazelnuts $(p<0.05)$. The AV values of samples roasted in $160{ }^{\circ} \mathrm{C}$ for 60 min were about 20 and 12.5 times higher for shelled and in-shell hazelnuts, respectively, as compared to unroasted nuts. It suggests that shell left during the roasting process had a protective function and limited hazelnuts oxidative deterioration. Additionally, there was noticeable regularity between $\mathrm{PV}$ and $\mathrm{AV}$ values presented in Table 1, samples with higher PV had lower AV and vice versa.

Since PV and AV present only part of oil oxidation status, total oxidation (TOTOX) value, marker of oil oxidative history and current oxidation status was calculated as well. The high quality oils should have TOTOX value $<10$ (Rossell and Pritchard 1991; Škevin et al. 2012). The highest TOTOX index was observed for hazelnuts roasted without shell in the most radical conditions tested $\left(160{ }^{\circ} \mathrm{C}, 60 \mathrm{~min}\right.$.) and even if the TOTOX value changed significantly $(p<0.05)$, it did not exceed quality limits in any case.

Determining oxidative stability is a tedious and timeconsuming method when analysed at room temperature (Mateos et al. 2006), but even if accelerated methods like 
Table 1 Free fatty acids, peroxide and anisidine values and TOTOX value of oils obtained from roasted hazelnuts

\begin{tabular}{|c|c|c|c|c|c|c|c|c|c|}
\hline \multicolumn{2}{|c|}{ Roasting conditions } & \multirow{2}{*}{\multicolumn{2}{|c|}{$\frac{\text { Free fatty acids }}{\% \text { of oleic acid }}$}} & \multirow{2}{*}{\multicolumn{2}{|c|}{$\frac{\text { Peroxide value }}{\mathrm{meqO}_{2} / \mathrm{kg}}$}} & \multirow{2}{*}{\multicolumn{2}{|c|}{ Anisidine value }} & \multirow{2}{*}{\multicolumn{2}{|c|}{ TOTOX }} \\
\hline \multirow[t]{2}{*}{ Temperature $\left[{ }^{\circ} \mathrm{C}\right]$} & \multirow[t]{2}{*}{ Time $[\mathrm{min}]$} & & & & & & & & \\
\hline & & Shelled & In-shell & Shelled & In-shell & Shelled & In-shell & Shelled & In-shell \\
\hline Unroasted & & $0.09 \pm 0.00 \mathrm{~d}$ & $0.09 \pm 0.00 \mathrm{de}$ & $0.79 \pm 0.00 \mathrm{e}$ & $0.79 \pm 0.00 \mathrm{~b}$ & $0.23 \pm 0.03 \mathrm{e}$ & $0.23 \pm 0.03 \mathrm{ef}$ & $1.81 \pm 0.03 \mathrm{e}$ & $1.81 \pm 0.03 \mathrm{~d}$ \\
\hline 100 & 10 & $0.08 \pm 0.00 \mathrm{~d}$ & $0.08 \pm 0.00 \mathrm{e}$ & $0.99 \pm 0.00 \mathrm{cde}$ & $0.79 \pm 0.05 \mathrm{~b}$ & $1.53 \pm 0.01 \mathrm{e}$ & $0.09 \pm 0.01 \mathrm{f}$ & $2.20 \pm 0.01 \mathrm{e}$ & $1.66 \pm 0.08 \mathrm{~d}$ \\
\hline 100 & 30 & $0.15 \pm 0.01 \mathrm{c}$ & $0.14 \pm 0.00 \mathrm{~b}$ & $2.27 \pm 0.12 \mathrm{a}$ & $1.76 \pm 0.01 \mathrm{a}$ & $0.22 \pm 0.06 \mathrm{~d}$ & $0.27 \pm 0.03 \mathrm{ef}$ & $5.48 \pm 0.18 b$ & $3.78 \pm 0.04 \mathrm{a}$ \\
\hline 100 & 60 & $0.14 \pm 0.01 \mathrm{~cd}$ & $0.14 \pm 0.01 b$ & $1.39 \pm 0.01 \mathrm{~b}$ & $0.88 \pm 0.14 \mathrm{~b}$ & $0.95 \pm 0.11 \mathrm{c}$ & $0.82 \pm 0.08 \mathrm{~d}$ & $4.30 \pm 0.13 c$ & $2.58 \pm 0.37 b c$ \\
\hline 130 & 10 & $0.11 \pm 0.00 \mathrm{~cd}$ & $0.14 \pm 0.00 \mathrm{~b}$ & $0.88 \pm 0.14 \mathrm{de}$ & $0.48 \pm 0.01 \mathrm{c}$ & $0.36 \pm 0.05 \mathrm{e}$ & $0.11 \pm 0.01 \mathrm{f}$ & $2.12 \pm 0.23 \mathrm{e}$ & $1.06 \pm 0.01 \mathrm{e}$ \\
\hline 130 & 30 & $0.11 \pm 0.01 \mathrm{~cd}$ & $0.14 \pm 0.01 b c$ & $1.16 \pm 0.13 \mathrm{bcd}$ & $0.96 \pm 0.04 \mathrm{~b}$ & $0.73 \pm 0.16 \mathrm{~d}$ & $0.91 \pm 0.02 \mathrm{~cd}$ & $3.05 \pm 0.41 \mathrm{~d}$ & $2.83 \pm 0.11 \mathrm{~b}$ \\
\hline 130 & 60 & $0.33 \pm 0.02 b$ & $0.13 \pm 0.01 b c$ & nd & $0.10 \pm 0.00 \mathrm{~d}$ & $2.00 \pm 0.02 b$ & $1.67 \pm 0.07 \mathrm{~b}$ & $2.00 \pm 0.02 \mathrm{e}$ & $1.87 \pm 0.07 \mathrm{~d}$ \\
\hline 160 & 10 & $0.14 \pm 0.01 \mathrm{~cd}$ & $0.11 \pm 0.00 \mathrm{~cd}$ & $0.98 \pm 0.04 \mathrm{cde}$ & $0.79 \pm 0.06 \mathrm{~b}$ & $0.07 \pm 0.01 \mathrm{e}$ & $0.46 \pm 0.01 \mathrm{e}$ & $2.03 \pm 0.10 \mathrm{e}$ & $2.04 \pm 0.10 \mathrm{cc}$ \\
\hline 160 & 30 & $0.10 \pm 0.00 \mathrm{~cd}$ & $0.12 \pm 0.01 \mathrm{bcd}$ & $1.27 \pm 0.09 \mathrm{bc}$ & $0.98 \pm 0.00 \mathrm{~b}$ & $1.28 \pm 0.03 \mathrm{c}$ & $1.08 \pm 0.14 \mathrm{c}$ & $3.81 \pm 0.16 \mathrm{c}$ & $3.04 \pm 0.14 \mathrm{~b}$ \\
\hline 160 & 60 & $0.52 \pm 0.04 \mathrm{a}$ & $0.34 \pm 0.01 \mathrm{a}$ & $1.16 \pm 0.00 \mathrm{bcd}$ & $0.43 \pm 0.04 \mathrm{c}$ & $4.56 \pm 0.13 \mathrm{a}$ & $2.89 \pm 0.04 \mathrm{a}$ & $6.88 \pm 0.13 \mathrm{a}$ & $3.75 \pm 0.05 \mathrm{a}$ \\
\hline
\end{tabular}

Data expressed as means \pm standard deviation $(n=3)$. The different lower case letters $(\mathrm{a}-\mathrm{f})$ in the same column indicate significantly different values $(p<0.05)$

Rancimat are applied, the time of one analysis can last long. In the present study, to get a complete picture of the oxidative stability of oil cold pressed from roasted hazelnuts, PDSC measurements were conducted. Results obtained at $140{ }^{\circ} \mathrm{C}$ are presented in Table 2. As reported previously (Ciemniewska-Żytkiewicz et al. 2014b), statistically significant linear correlations between PDSC maximum induction time $\left(\tau_{\max }\right)$ and the Rancimat values imply that PDSC can be recommended as an appropriate unbiased method for assessing the oxidative stability of hazelnut oils. According to Ciemniewska-Żytkiewicz et al. 2014b, the Pearson correlation $(R>0.99)$ (Eq. 1) enabled the authors to express, herein, the obtained results of oxidative stability through Rancimat induction time, as well (Table 2.). $\tau_{\text {Racimat }[h]}=0.0446 \tau_{\mathrm{PDSC}[\min ]}+0.1815$

The results of $\tau_{\max }$ were in the range of 31.52-39.49 and 31.65-38.33 min for shelled and in-shell hazelnuts, respectively. As a resultant of all changes that occurred, the oxidative stability was slightly elevated with the increased temperature and time of roasting process. The highest oxidative stability levels for both shelled and in-shell hazelnuts were noticed after $130{ }^{\circ} \mathrm{C} / 60 \mathrm{~min}$ of roasting process $(p<0.05)$; however, all the results obtained confirmed high overall oil oxidative quality.

Isothermal pressure DSC conducted in $140{ }^{\circ} \mathrm{C}$ was previously used to determine oxidative stability of selected fresh
Table 2 Oxidation stability of oils obtained from roasted hazelnut
Data expressed as means \pm standard deviation $(n=3)$. The different lower case letters $(\mathrm{a}-\mathrm{h})$ in the same column indicate significantly different values $(p<0.05)$

${ }^{a}$ Calculated based on Ciemniewska-Żytkiewicz et al. 2014b

\begin{tabular}{|c|c|c|c|c|c|}
\hline \multicolumn{2}{|l|}{ Roasting conditions } & \multicolumn{2}{|l|}{ PDSC } & \multicolumn{2}{|c|}{ Rancimat in $140{ }^{\circ} \mathrm{C}^{\mathrm{a}}$} \\
\hline \multirow[t]{2}{*}{ Temperature $\left[{ }^{\circ} \mathrm{C}\right]$} & \multirow[t]{2}{*}{ Time $[\mathrm{min}]$} & \multicolumn{2}{|l|}{$\min$} & \multicolumn{2}{|l|}{$\mathrm{h}$} \\
\hline & & Shelled & In-shell & Shelled & In-shell \\
\hline Unroasted & & $32.54 \pm 0.16 \mathrm{~g}$ & $32.54 \pm 0.16 \mathrm{e}$ & $1.63 \pm 0.01$ & $1.63 \pm 0.01$ \\
\hline 100 & 10 & $31.52 \pm 0.04 \mathrm{~h}$ & $34.81 \pm 0.06 \mathrm{~b}$ & $1.59 \pm 0.01$ & $1.63 \pm 0.01$ \\
\hline 100 & 30 & $35.19 \pm 0.09 \mathrm{~d}$ & $32.92 \pm 0.09 \mathrm{e}$ & $1.75 \pm 0.01$ & $1.73 \pm 0.01$ \\
\hline 100 & 60 & $34.27 \pm 0.13 \mathrm{e}$ & $31.84 \pm 0.18 \mathrm{f}$ & $1.71 \pm 0.01$ & $1.65 \pm 0.01$ \\
\hline 130 & 10 & $36.87 \pm 0.13 \mathrm{c}$ & $33.99 \pm 0.01 \mathrm{~cd}$ & $1.83 \pm 0.01$ & $1.70 \pm 0.01$ \\
\hline 130 & 30 & $38.68 \pm 0.04 b$ & $31.65 \pm 0.08 \mathrm{f}$ & $1.91 \pm 0.01$ & $1.59 \pm 0.01$ \\
\hline 130 & 60 & $39.49 \pm 0.11 \mathrm{a}$ & $38.33 \pm 0.40 \mathrm{a}$ & $1.94 \pm 0.01$ & $1.89 \pm 0.02$ \\
\hline 160 & 10 & $32.67 \pm 0.08 \mathrm{~g}$ & $34.72 \pm 0.16 b$ & $1.64 \pm 0.01$ & $1.73 \pm 0.01$ \\
\hline 160 & 30 & $33.65 \pm 0.03 f$ & $33.62 \pm 0.03 \mathrm{~d}$ & $1.68 \pm 0.01$ & $1.68 \pm 0.01$ \\
\hline 160 & 60 & $36.65 \pm 0.23 c$ & $34.53 \pm 0.03 b c$ & $1.82 \pm 0.01$ & $1.72 \pm 0.01$ \\
\hline
\end{tabular}


vegetable oils (Kowalski et al. 2004; CiemniewskaŻytkiewicz et al. 2014b). Thus, Kowalski et al. (2004) reported $\tau_{\max }$ accounted for 22.0, 21.8 and $9.5 \mathrm{~min}$ for rapeseed, soybean and sunflower oils, while Ciemniewska-Żytkiewicz et al. (2014b) reported ranges 44.21-26.44, 39.20-27.47 and 22.85-17.66 min for hazelnut, olive and rapeseed oils, respectively. Therefore, the oxidative stability level of oil from roasted hazelnuts obtained herein seemed to be comparable or even higher than previously reported. It could be partially explained by the Maillard reaction products formation through the interaction of proteins with reducing sugars during hightemperature roasting treatment (Elizade et al. 1991). As reported by Michalska and Zieliński (2007), melanoidins, products of non-enzymatic browning, reportedly show strong antioxidant activity which can affect positively oxidative stability of tested hazelnuts.

In the present study, the highest results of Rancimat induction period (IP) values calculated accounted for almost $2 \mathrm{~h}$ for roasted hazelnuts (Table 2.). In the majority of papers on oxidative stability, Rancimat analyses are performed at 110 or $120^{\circ} \mathrm{C}$ (Hassanien et al. 2014; Gharby et al. 2011); however, the Rancimat results are repetitive even at $140{ }^{\circ} \mathrm{C}$ (Mateos et al. 2006). IP values obtained in $140{ }^{\circ} \mathrm{C}$ for olive oils were in the range of 0.9 to $9.8 \mathrm{~h}$ (Mateos et al. 2006), and the results obtained herein for hazelnut oils were within the range presented for olive oil.

\section{Fatty Acid Composition}

As the fatty acids composition can be treated as an indicator of its susceptibility to oxidation, it could be used as a part of overall oxidation status description of hazelnut oil. In the raw Kataloński variety, 15 different fatty acids were detected, as previously reported (CiemniewskaŻytkiewicz et al. 2015). In the present study, some minor changes in the fatty acid composition in roasted hazelnuts (both shelled and in-shell) were observed, and the data on selected fatty acids levels are gathered in Table 3. In general, there was a relationship observed between particular fatty acids percentage relative content and increasing roasting temperature and time of exposure. Slight but significant $(p<0.05)$ increases in saturated fatty acid (palimitic and stearic) relative levels were observed for both shelled and in-shell roasted hazelnuts especially heated in the highest temperature tested $-160{ }^{\circ} \mathrm{C}$. In the case of oleic acid, the relative levels were found to be changed individually with no convergent pattern $(p<0.05)$; however, even the biggest change was negligible (maximum $2.5 \%$ ).

In general, higher level of unsaturation favours oxidation process, for instance, by thermal processing, such as, dry roasting treatment. The autooxidation rates of oleic, linoleic, and linolenic fatty acids relate to degree of unsaturation and are 1:40:100, respectively (Frankel 1985; Arranz et al. 2008; Ciemniewska-Żytkiewicz et al. 2014b). Because of that, the C18:2 $\omega 6$ and $\mathrm{C} 18: 3 \omega 3$ fatty acids should be more susceptible to the roasting process, especially in higher temperatures. Herein, for most roasting conditions studied, C18:2 $\omega 6$ relative level decreased $(p<0.05)$ with some exceptions (Table 3$)$; however, C18:3 w3 and C16:1 levels were constant apart from increasing roasting temperatures, times of exposure and protective role of the shell. It could be explained by no relative changes occurring but also by the very low level of these FAs in tested samples and low results accuracy (first decimal place only). The results obtained are mostly consistent with other previously published papers on hazelnuts (Amaral et al. 2006), where authors noticed the modest increase in oleic and saturated fatty acids and a decrease of linoleic acid, as temperatures and roasting periods increased. On the other hand, the fatty acid profiles in several foodstuffs (walnuts, safflower seeds and chestnuts) previously subjected to the thermal treatment had not been changed significantly (Künsch et al. 2001; Lee et al. 2004; Vaidya and Eun 2013).

\section{Tocopherol Content}

Hazelnuts are an excellent source of tocopherols (Kornsteriner et al. 2006; Savage et al. 1997; Matth us and Özcan 2012; Ciemniewska-Żytkiewicz et al. 2015), strong antioxidants with significant biological effect, so these compounds are thought to be nutritionally valued in the human diet. The contents of the individual and total tocopherols in hazelnut oils obtained at various roasting temperatures and times of exposure are given in Table 4. Three compounds were detected and quantified ( $\alpha-, \beta-, \gamma$-tocopherols), whereas in all samples, $\alpha$ tocopherol was the predominant component, followed by $\gamma$ and $\beta$-homologues, respectively.

Herein, with increasing roasting time and temperature, the three homologues presented different behaviours, with no apparent variability (Table 4). It could be ascribed by two opposed effects, such as, the tocopherol levels reduced and increased yield of extraction, both caused by thermal processing. Tocopherol levels can be reduced during roasting by the oxidation process and thermal degradation (Rossi et al. 2001; Alamprese et al. 2009); however, on the other hand, tocols are bound to the membrane and are linked to other compounds, such as phospholipids. They can be more easily released by heat treatment resulting in their higher concentration in oil (Amaral et al. 2006; Lee et al. 2004).

The $\alpha$-tocopherol levels showed minor changes after the roasting treatment, however not statistically significant $(p<0.05)$. The biggest losses were observed for $\gamma$-tocopherol, which accounted for over $20 \%$ for $100^{\circ} \mathrm{C} / 30$ min and $160{ }^{\circ} \mathrm{C} /$ 
Table 3 Selected fatty acid composition in oils obtained from roasted hazelnuts

\begin{tabular}{|c|c|c|c|c|c|c|c|c|c|c|c|c|c|}
\hline \multicolumn{2}{|l|}{ Roasting conditions } & \multicolumn{12}{|c|}{ Fatty acid (mg/100 mg FAME) } \\
\hline \multirow[t]{2}{*}{ Temperature $\left[{ }^{\circ} \mathrm{C}\right]$} & \multirow[t]{2}{*}{ Time [min] } & \multicolumn{2}{|l|}{ C16:0 } & \multicolumn{2}{|l|}{ C16:1 } & \multicolumn{2}{|l|}{$\mathrm{C} 18: 0$} & \multicolumn{2}{|c|}{ C18:1 $\omega 9$} & \multicolumn{2}{|c|}{$\mathrm{C} 18: 2 \omega 6$} & \multicolumn{2}{|c|}{$\mathrm{C} 18: 3 \omega 3$} \\
\hline & & Shelled & In-shell & Shelled & In-shell & Shelled & In-shell & Shelled & In-shell & Shelled & In-shell & Shelled & In-shell \\
\hline unroasted & & $4.7 \mathrm{ef}$ & $4.7 \mathrm{bc}$ & $0.2 \mathrm{a}$ & $0.2 \mathrm{a}$ & $1.5 \mathrm{bcd}$ & $1.5 \mathrm{bc}$ & $80.4 \mathrm{bc}$ & $80.4 d$ & $13.2 \mathrm{bc}$ & $13.2 \mathrm{a}$ & $0.1 \mathrm{a}$ & $0.1 \mathrm{a}$ \\
\hline 100 & 10 & $5.2 \mathrm{bc}$ & $4.6 \mathrm{c}$ & $0.2 \mathrm{a}$ & $0.2 \mathrm{a}$ & $1.7 \mathrm{a}$ & $1.4 \mathrm{~cd}$ & $80.3 \mathrm{bc}$ & $82.3 \mathrm{a}$ & $12.3 \mathrm{f}$ & $12.0 \mathrm{~d}$ & $0.1 \mathrm{a}$ & $0.1 \mathrm{a}$ \\
\hline 100 & 30 & $5.0 \mathrm{~cd}$ & $5.0 \mathrm{a}$ & $0.2 \mathrm{a}$ & $0.2 \mathrm{a}$ & $1.7 \mathrm{a}$ & $1.7 \mathrm{a}$ & $80.1 \mathrm{c}$ & 79.9ef & $12.8 \mathrm{e}$ & $12.8 \mathrm{~b}$ & $0.1 \mathrm{a}$ & $0.1 \mathrm{a}$ \\
\hline 100 & 60 & $4.1 \mathrm{~g}$ & $4.3 \mathrm{~d}$ & $0.2 \mathrm{a}$ & $0.2 \mathrm{a}$ & $1.4 \mathrm{~cd}$ & $1.2 \mathrm{~d}$ & $81.8 \mathrm{a}$ & $81.6 \mathrm{~b}$ & $12.4 \mathrm{f}$ & $12.6 b$ & $0.1 \mathrm{a}$ & $0.1 \mathrm{a}$ \\
\hline 130 & 10 & $4.5 \mathrm{f}$ & $4.5 \mathrm{c}$ & $0.2 \mathrm{a}$ & $0.2 \mathrm{a}$ & $1.3 \mathrm{~d}$ & $1.4 \mathrm{~cd}$ & $81.8 \mathrm{a}$ & $81.8 \mathrm{~b}$ & $11.8 \mathrm{~g}$ & $11.8 \mathrm{~d}$ & $0.1 \mathrm{a}$ & $0.1 \mathrm{a}$ \\
\hline 130 & 30 & 4.6ef & $4.8 \mathrm{~b}$ & $0.2 \mathrm{a}$ & $0.2 \mathrm{a}$ & $1.5 \mathrm{abc}$ & $1.6 \mathrm{ab}$ & $80.5 b$ & $79.7 \mathrm{f}$ & $12.8 \mathrm{de}$ & $13.3 \mathrm{a}$ & $0.1 \mathrm{a}$ & $0.1 \mathrm{a}$ \\
\hline 130 & 60 & $4.8 \mathrm{de}$ & $5.1 \mathrm{a}$ & $0.2 \mathrm{a}$ & $0.2 \mathrm{a}$ & $1.5 \mathrm{abc}$ & $1.6 \mathrm{ab}$ & $81.5 \mathrm{a}$ & $80.5 \mathrm{~cd}$ & $11.7 \mathrm{~g}$ & $12.2 \mathrm{c}$ & $0.1 \mathrm{a}$ & $0.1 \mathrm{a}$ \\
\hline 160 & 10 & $4.8 \mathrm{def}$ & $4.8 \mathrm{~b}$ & $0.2 \mathrm{a}$ & $0.2 \mathrm{a}$ & $1.6 \mathrm{ab}$ & $1.7 \mathrm{a}$ & $79.5 \mathrm{~d}$ & $80.7 \mathrm{c}$ & $13.5 \mathrm{a}$ & $12.3 \mathrm{c}$ & $0.1 \mathrm{a}$ & $0.1 \mathrm{a}$ \\
\hline 160 & 30 & $5.5 \mathrm{a}$ & $4.8 b$ & $0.2 \mathrm{a}$ & $0.2 \mathrm{a}$ & $1.7 \mathrm{a}$ & $1.6 \mathrm{ab}$ & $78.8 \mathrm{e}$ & $80.1 \mathrm{e}$ & $13.4 \mathrm{ab}$ & $12.8 \mathrm{~b}$ & $0.1 \mathrm{a}$ & $0.1 \mathrm{a}$ \\
\hline 160 & 60 & $5.3 \mathrm{ab}$ & $4.8 \mathrm{~b}$ & $0.2 \mathrm{a}$ & $0.2 \mathrm{a}$ & $1.6 \mathrm{ab}$ & $1.6 \mathrm{ab}$ & $79.4 d$ & $79.8 \mathrm{f}$ & $13.1 \mathrm{~cd}$ & $13.1 \mathrm{a}$ & $0.1 \mathrm{a}$ & $0.1 \mathrm{a}$ \\
\hline
\end{tabular}

Data expressed as means \pm standard deviation $(n=3)$, The different lower case letters $(\mathrm{a}-\mathrm{f})$ in the same column indicate significantly different values $(p<0.05)$

30 min roasting without shell, when compared to the raw values. Herein, considering the results of all tocopherol homologues, $\alpha$ - homologue seemed to be most and $\beta$-, the least resistant to roasting conditions applied, which is in wide agreement with Amaral et al. (2006), but not necessarily with other literature available (Barrera-Arellano et al. 1999; Yoshida et al. 1993).

In general, after all roasting treatments studied for shelled and in-shell hazelnuts, the amount of total tocopherols was still over $95 \%$ of the original levels. Similar results were obtained previously for hazelnuts (Amaral et al. 2006), peanuts (Yoshida et al. 2003) and sunflower seeds (Yoshida et al.
2002), with at least 90,85 and $90 \%$ of tocols recovery after roasting process, respectively.

\section{MID-FT-IR Analysis}

Spectra registered for 27 roasted samples $\left(160{ }^{\circ} \mathrm{C}, 30\right.$ and $60 \mathrm{~min}$ ) and five raw samples were analysed due to differences between the three groups: roasted in shells - group 1 (11 samples), roasted shelled - group 2 (16 samples) and raw - group 3 (5 samples). Initially, visual inspection of the studied spectra was conducted. No significant differences were observed, although some slight discrepancies between the most

Table 4 Tocopherols content in oils obtained from roasted hazelnuts

\begin{tabular}{|c|c|c|c|c|c|c|c|c|c|}
\hline \multicolumn{2}{|l|}{ Roasting conditions } & \multirow{2}{*}{\multicolumn{2}{|c|}{$\frac{\alpha \text {-Tocopherol }}{\mathrm{mg} / \mathrm{kg} \text { oil }}$}} & \multicolumn{2}{|l|}{$\gamma$-Tocopherol } & \multicolumn{2}{|l|}{$\beta$-Tocopherol } & \multicolumn{2}{|l|}{ Total } \\
\hline \multirow[t]{2}{*}{ Temperature $\left[{ }^{\circ} \mathrm{C}\right]$} & \multirow[t]{2}{*}{ Time [min] } & & & & & & & & \\
\hline & & Shelled & In-shell & Shelled & In-shell & Shelled & In-shell & Shelled & In-shell \\
\hline Unroasted & & $320.4 \pm 17.8 \mathrm{a}$ & $320.4 \pm 17.8 \mathrm{a}$ & $14.5 \pm 0.5 \mathrm{ab}$ & $14.5 \pm 0.5 b c$ & $7.6 \pm 0.2 \mathrm{bcd}$ & $7.6 \pm 0.2 b$ & 342.6 & \\
\hline 100 & 10 & $328.7 \pm 14.5 \mathrm{a}$ & $315.3 \pm 10.4 \mathrm{a}$ & $11.1 \pm 0.3 \mathrm{e}$ & $12.4 \pm 0.2 \mathrm{e}$ & $7.6 \pm 0.6 \mathrm{bcd}$ & $7.3 \pm 0.3 \mathrm{bc}$ & 347.4 & 335.0 \\
\hline 100 & 30 & $306.0 \pm 3.2 \mathrm{a}$ & $318.4 \pm 4.8 \mathrm{a}$ & $13.0 \pm 0.5 \mathrm{bcd}$ & $12.5 \pm 0.7 \mathrm{e}$ & $6.6 \pm 0.5 \mathrm{~d}$ & $6.9 \pm 0.2 \mathrm{~cd}$ & 325.5 & 337.9 \\
\hline 100 & 60 & $326.7 \pm 1.3 \mathrm{a}$ & $320.4 \pm 1.1 \mathrm{a}$ & $13.1 \pm 0.2 \mathrm{bcd}$ & $12.9 \pm 0.1 \mathrm{de}$ & $8.7 \pm 0.1 \mathrm{ab}$ & $6.6 \pm 0.1 \mathrm{~d}$ & 348.4 & 340.0 \\
\hline 130 & 10 & $319.5 \pm 2.2 \mathrm{a}$ & $332.9 \pm 9.8 \mathrm{a}$ & $15.7 \pm 0.5 \mathrm{a}$ & $13.5 \pm 0.3 \mathrm{cde}$ & $9.0 \pm 0.3 \mathrm{a}$ & $7.5 \pm 0.1 \mathrm{bc}$ & 344.2 & 353.9 \\
\hline 130 & 30 & $332.6 \pm 8.1 \mathrm{a}$ & $326.7 \pm 0.1 \mathrm{a}$ & $15.9 \pm 0.8 \mathrm{a}$ & $14.9 \pm 0.2 \mathrm{~b}$ & $7.9 \pm 0.1 \mathrm{abc}$ & $7.6 \pm 0.0 \mathrm{~b}$ & 356.4 & 349.1 \\
\hline 130 & 60 & $317.0 \pm 2.5 \mathrm{a}$ & $311.5 \pm 4.1 \mathrm{a}$ & $13.9 \pm 0.1 b c$ & $14.9 \pm 0.1 \mathrm{~b}$ & $7.0 \pm 0.1 \mathrm{~cd}$ & $7.9 \pm 0.1 b$ & 337.8 & 334.3 \\
\hline 160 & 10 & $320.1 \pm 4.7 \mathrm{a}$ & $320.3 \pm 1.6 \mathrm{a}$ & $12.5 \pm 0.0 \mathrm{cde}$ & $14.2 \pm 0.4 \mathrm{bcd}$ & $7.6 \pm 0.1 \mathrm{bcd}$ & $7.5 \pm 0.1 \mathrm{bc}$ & 340.2 & 342.1 \\
\hline 160 & 30 & $308.3 \pm 7.1 \mathrm{a}$ & $314.0 \pm 6.8 \mathrm{a}$ & $11.6 \pm 0.3 \mathrm{de}$ & $17.6 \pm 0.3 \mathrm{a}$ & $7.2 \pm 0.4 \mathrm{~cd}$ & $7.7 \pm 0.1 \mathrm{~b}$ & 327.1 & 339.2 \\
\hline 160 & 60 & $321.7 \pm 6.6 \mathrm{a}$ & $320.4 \pm 0.7 \mathrm{a}$ & $14.3 \pm 0.5 \mathrm{ab}$ & $13.3 \pm 0.3 \mathrm{cde}$ & $8.2 \pm 0.2 \mathrm{abc}$ & $8.7 \pm 0.2 \mathrm{a}$ & 344.2 & 342.4 \\
\hline
\end{tabular}

Data expressed as means \pm standard deviation $(n=3)$. The different lower case letters $(\mathrm{a}-\mathrm{d})$ in the same column indicate significantly different values $(p<0.05)$ 
distinctive spectra were observed in the regions: $1660 \mathrm{~cm}^{-1}$, $878 \mathrm{~cm}^{-1}, 708 \mathrm{~cm}^{-1}$ and $689-672 \mathrm{~cm}^{-1}$, respectively. This procedure did not however provide with the expected sufficient data to select distinctive groups of differently treated hazelnuts.

Visual inspection was followed by software digital analysis that considered mutual interaction of spectral changes (intensity and wave number) in different spectral regions. Three groups (raw, roasted in and out of shells) were successfully differentiated by discriminant analysis from the TQ analyst software with use of eight principal components, covering cumulatively $99.98 \%$ of total variance. One hundred percent samples were correctly classified. Figure 1 shows discriminant analysis with three separate groups rounded with circles-dashed line circle for in-shell roasted group of hazelnuts, dotted for raw and regular line for shelled samples. Although only five samples have been used as a raw material representative against 16 and 11 samples representing roasted samples, respectively, statistically significant differentiation with PI equal to 88.71 was determined. All the groups are quite condensed, with members being relatively close to each other (the mean Machalanobis distance within group 1, 2 and 3 were $1.01 \pm 0.18 ; 0.89 \pm 0.23$ and $0.86 \pm 0.25$, respectively). Additionally, Fig. 1 shows that group 2 is significantly closer to group 3 then to group 1, with corresponding mean Machalanobis distances between groups $1 / 3$ and $2 / 3$ accounted for $1.59 \pm 0.30$ and $2.01 \pm 0.34$, respectively. This observation suggests that chemically, roasted hazelnuts in shells are more similar to raw material and shell left for roasting treatment protects nuts significantly against changes occurring during hightemperature processing. This protective effect delays fat oxidation mainly, which can reasonably be confirmed by values of total oxidation status (Table 1). The spectral regions selected to distinguish three groups, i.e. 3530-
$3430,1820-1660$ and $1480-1370 \mathrm{~cm}^{-1}$, respectively, confirms this hypothesis, as similar spectral regions are quoted in the literature to be responsible for chemical alterations in fats during oxidation. As reported previously, the peroxides formation is responded by changes in the region of 3560-3360 $\mathrm{cm}^{-1}$ (Guillén and Cabo 2002). Changes within region $1820-1660 \mathrm{~cm}^{-1}$ that cover regions related to alterations in $\mathrm{C}=\mathrm{O}$ vibrations of the aldehydes (1739 to $1724 \mathrm{~cm}^{-1}$ ) and ketones (1724 to $1709 \mathrm{~cm}^{-1}$ ) (Sadoudi et al. 2013). Region $1480-1370 \mathrm{~cm}^{-1}$ is related to bending vibrations of $\mathrm{CH}_{2}$ groups, rocking vibrations of $\mathrm{CH}$ bonds of cis-disubstituted olefins and bending in plane vibrations of $\mathrm{CH}$ cis-olefinic groups (Vlachos et al. 2006). However, based on obtained IR data, it is not possible to state whether fat oxidation deletion for in-shell samples occurs due to shifting onset point of oxidation or any other mechanism.

\section{Conclusions}

The results of PDSC and reference methods obtained within this study both evaluated overall oxidative stability of roasting hazelnuts. They showed only slight effect of roasting conditions on quality and nutritional value of processed hazelnuts. Tocopherols are known to act as antioxidant and their content increases oxidative stability in general. Within this study, the level of tocopherols was reported to decrease during roasting. Interestingly, even though slight decrease of tocopherols occurred (up to $5 \%$ ), the oxidative stability did not drop down, but conversely increased slightly (by $\sim 21$ and $\sim 18 \%$ for shelled and in-shell hazelnuts, respectively) with statistical significance $(p<0.05)$. The highest values of oxidative stability were obtained for roasting process performed at $130^{\circ} \mathrm{C}$ for $60 \mathrm{~min}$.
Fig. 1 Discriminant analysis forming three homologous groups of raw, shelled and in-shell roasted hazelnuts

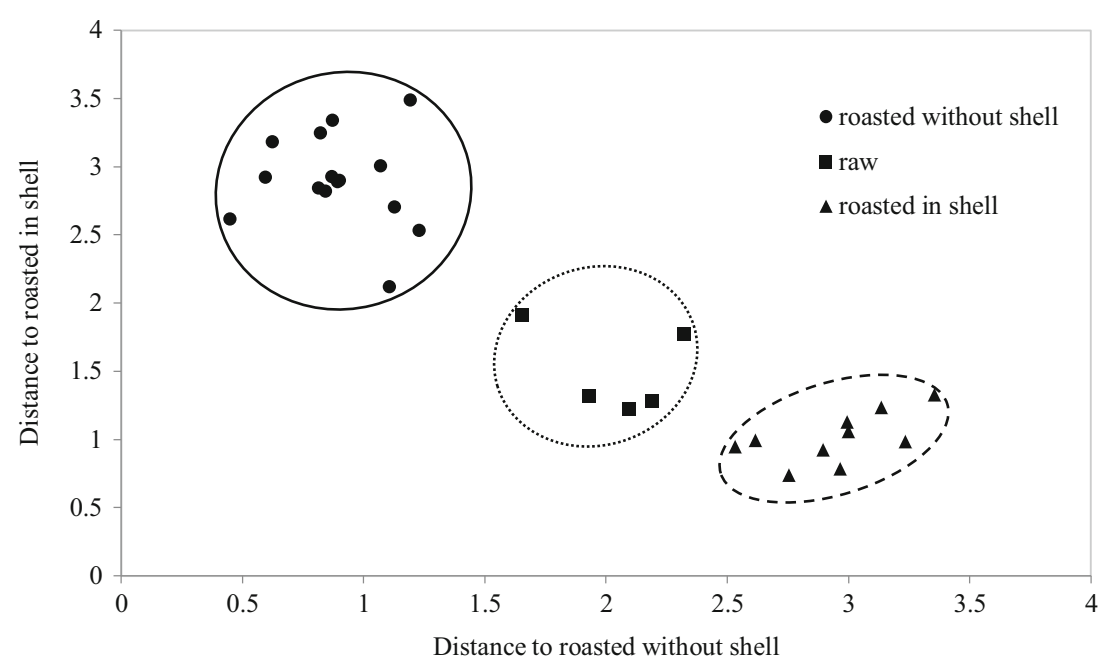


Interpretation of statistically processed MID-FT-IR data proved that the protective role of the shell during roasting, as in-shell processed hazelnuts were more similar to raw material than to shelled ones, in terms of chemical composition. The spectral regions selected for distinguishing studied groups evidenced that the protective role is based on delaying the oxidation process. Studies conducted perceive IR as a valuable method for hazelnuts quality control and technological process monitoring.

Acknowledgments This publication has been co-financed with the European Union funds by the European Social Fund. The authors wish to thank Mr. Patrick MacNeil who assisted in the proof-reading and linguistic corrections of the manuscript.

Conflict of Interest Hanna Ciemniewska-Żytkiewicz declares that he has no conflict of interest. Joanna Bryś declares that he has no conflict of interest. Katarzyna Sujka declares that he has no conflict of interest. Piotr Koczon declares that he has no conflict of interest. This article does not contain any studies with human or animal subjects.

Open Access This article is distributed under the terms of the Creative Commons Attribution License which permits any use, distribution, and reproduction in any medium, provided the original author(s) and the source are credited.

\section{References}

Alamprese C, Ratti S, Rossi M (2009) Effects of roasting conditions on hazelnut characteristics in a two-step process. J Food Eng 95:272279

Alasalvar C, Pelvan E, Topal B (2010) Effects of roasting on oil and fatty acid composition of Turkish hazelnut varieties (Corylus avellana L.). Int J Food Sci Nutr 61:630-642

Amaral J, Casal S, Seabra R, Oliveira B (2006) Effects of roasting on hazelnut lipids. J Agric Food Chem 54:1315-1321

Arranz S, Cert R, Pérez-Jiménez J, Cert A, Saura-Calixto F (2008) Comparison between free radical scavenging capacity and oxidative stability of nut oils. Food Chem 110:985-990

Barrera-Areallano D, Ruiz-Méndez V, Ruiz GM, Dobarganes C (1999) Loss of tocopherols and formation of degradation compounds in triacylglycerol model systems heated at high temperature. J Sci Food Agri 79:1923-1928

Bevilacqua M, Bucci R, Materazzi S, Marini F (2013) Application of near infrared (NIR) spectroscopy coupled to chemometrics for dried eggpasta characterization and egg content quantification. Food Chem 140:726-734

Bryś J, Wirkowska M, Górska A, Ostrowska-Ligęza E, Bryś A, Koczoń P (2013) The use of DSC and FT-IR spectroscopy for evaluation of oxidative stability of interesterified fats. J Therm Anal Calorim 112: 481-487

Christie WW (1982) A simple procedure for rapid transmethylation of glycerolipids and cholesteryl esters. J Lipid Res 23:1072-1075

Ciemniewska-Żytkiewicz H, Bryś J, Bryś A, Sujka K, Koczoń P (2014a) Effect of roasting process on moisture content and colour of Polish inshell hazelnuts. Acad Food J 12:6-10

Ciemniewska-Żytkiewicz H, Bryś J, Ratusz K, Reder M, Koczoń P (2014b) Determination of the oxidative stability of hazelnut oils by PDSC and Rancimat methods. J Therm Anal Calorim. doi:10.1007/ s10973-014-3861-9
Ciemniewska-Żytkiewicz H, Verardo V, Pasini F, Bryś J, Koczoń P, Caboni MF (2015) Determination of lipid and phenolic fraction in two hazelnut (Corylus avellana L.) cultivars grown in Poland. Food Chem 168:615-622

Codex Standard for Edible Fats and Oils not covered by individual standards, CODEX Stan 19-1981, Amend. 2-2013, (www. codexalimentarius.org/standards/list-of-standards)

Demir AD, Cronin K (2005) Modelling the kinetics of textural changes in hazelnuts during roasting. Simul Model Pract Th 3:97-107

Donno D, Beccaro GL, Mellano GM, Di Prima S, Cavicchiolo M, Cerutti AK, Bounous G (2013) Setting a protocol for hazelnut roasting using sensory and colorimetric analysis: influence of the roasting temperature on the quality of Tonda gentile delle Langhe Cv. hazelnut. Czech J Food Sci 31:390-400

Elizade BE, Rosa MD, Lerici CR (1991) Effects of Maillard reaction volitiles products on lipid oxidation. J Am Oil Chem Soc 68:758 762

Frankel EN (1985) Chemistry of free radical and singlet oxidation of lipids. Prog Lipid Res 23:197-221

Gharby S, Harhar H, Guillaume D, Haddad A, Matthäus B, Charrouf Z (2011) Oxidative stability of edible argan oil: a two-year study. LWT-Food Sci Technol 44:1-8

Gómez-Caravaca AM, Verardo V, Caboni MF (2010) Chromatographic techniques for the determination of alkyl-phenols, tocopherols and other minor polar compounds in raw and roasted cold pressed cashew nut oils. J Chromatogr A 1217:7411-7417

Guillén MD, Cabo N (2002) Fourier transform infrared spectra data versus peroxide and anisidine values to determine oxidative stability of edible oils. Food Chem 77:503-510

Hassanien MMM, Abdel-Razek AG, Rudzińska M, Siger A, Ratusz K, Przybylski R (2014) Phytochemical contents and oxidative stability of oils from non-traditional sources. Eur J Lipid Sci Technol. doi:10. 1002/ejlt.201300475

ISO 3960:2007. Animal and vegetable fats and oils - Determination of Peroxide Value - Iodometric (Visual) Endpoint Determination. International Organization for Standardization, Geneva, Switzerland

ISO 660:2009. Animal and vegetable fats and oils - Determination of acid value and acidity. International Organization for Standardization, Geneva, Switzerland

ISO 6885:2012. Animal and vegetable fats and oils - Determination of Anisidine Value - International Organization for Standardization, Geneva, Switzerland

Kornsteriner M, Wagner KH, Elmadfa I (2006) Tocopherols and total phenolics in 10 different nut types. Food Chem 98:381-387

Kowalski B, Ratusz K, Kowalska D, Bekas W (2004) Determination of oxidative stability of vegetable oils by differential scanning calorimetry and Rancimat measurements. Eur J Lipid Sci Technol 106:165169

Künsch U, Schärer H, Patrian B, Höhn E, Conedera M, Sassella A, Jermini M, Jelmini G (2001) Effects of roasting on chemical composition and quality of different chestnut (Castanea sativa Mill) varieties. J Sci Food Agr 81:1106-1112

Lee YC, Oh SW, Chang J, Kim IH (2004) Chemical composition and oxidative stability of safflower oil prepared from safflower seed roasted with different temperatures. Food Chem 84:1-6

Mateos R, Uceda M, Aguilera MP, Escuderos ME, Maza GB (2006) Relationship of Rancimat method values at varying temperatures for virgin olive oils. Eur Food Res Technol 223:246-252

Matth us B, Özcan MM (2012) The comparison of properties of the oil and kernels of various hazelnuts from Germany and Turkey. Eur J Lipid Sci Technol 114:801-806

Michalska A, Zieliński H (2007) Produkty reakcji Maillarda w żywności. Żywność-Nauka Technol Ja 51:5-16

Özdemir M, Devres O (1999) The thin layer drying characteristics of hazelnuts during roasting. J Food Eng 42:225-233 
Özdemir M, Devres O (2000) Analysis of color development during roasting of hazelnuts using response surface methodology. J Food Eng 45:17-24

Perren R, Escher FE (1997) Investigations on the hot air roasting of nuts. Manuf Confectioner 6:123-127

Rossell JB, Pritchard JLR (1991) Analysis of oilseeds, fats and fatty foods. Elsevier Science Publishers Ltd, Amsterdam, The Netherlands, pp 25-26

Rossi M, Gianazza M, Alamprese C, Stanga F (2001) The effect of bleaching and physical refining on color and minor components of palm oil. J Am Oil Chem Soc 78:1051-1055

Sadoudi R, Ammouche A, Ali Ahmed D (2013) Thermal oxidative alteration of sunflower oil. Afr J Food Sci 8:116-121

Savage GP, McNeil DL, Dutta PC (1997) Lipid composition and oxidative stability of oils in hazelnuts (Corylus avellana L.) grown in New Zealand. J Am Chem Soc 74:755-759

Sherazi STH, Younis Talpur M, Mahesar SA, Kandhro AA, Arain S (2009) Main fatty acid classes in vegetable oils by SB-ATRFourier transform infrared (FTIR) spectroscopy. Talanta 80:600 606

Škevin D, Domijan T, Kraljić K, Kljusurić JG, Neđeral S, Obranović M (2012) Optimization of bleaching parameters for soybean Oil. Food Technol Biotechnol 50:199-207
Tan CP, Che Man YB, Selamat J, Yusoff MSA (2002) Comparative studies of oxidative stability of edible oils by differential scanning calorimetry and oxidative stability index methods. Food Chem 76: 385-389

Vaidya B, Eun JB (2013) Effect of roasting on oxidative and tocopherol stability of walnut oil during storage in the dark. Eur J Lipid Sci Technol 113:348-355

Vlachos N, Skopelitis Y, Psaroudaki M, Konstantinidou V, Chatzilazarou A, Tegou E (2006) Applications of Fourier transform-infrared spectroscopy to edible oils. Anal Chim Acta 573-574:459-465

Yang H, Irudayaraj J, Paradkar MM (2005) Discriminant analysis of edible oils and fats by FTIR, FT-NIR and FT-Raman spectroscopy. Food Chem 93:25-32

Yoshida H, Hirakawa Y, Abea S, Mizushinaa Y (2002) The content of tocopherols and oxidative quality of oils prepared from sunflower (Helianthus annuus L.) seeds roasted in a microwave oven. Eur J Lipid Sci Technol 104:116-122

Yoshida H, Hirakawa Y, Tomiyama Y, Mizushinaa Y (2003) Effects of microwave treatment on the oxidative stability of peanut (Arachis hypogaea) oils and the molecular species of their triacylglycerols. Eur J Lipid Sci Technol 105:351-358

Yoshida H, Kajimoto G, Emura S (1993) Antioxidant effects of Dtocopherols at different concentrations in oils during microwave heating. J Am Oil Chem Soc 70:989-995 